Editorial

\title{
Hydrology: An International and Interdisciplinary Scientific Open Access Journal
}

\section{Okke Batelaan}

School of the Environment, Flinders University, GPO Box 2100, Adelaide SA 5001, Australia; E-Mail: okke.batelaan@flinders.edu.au; Tel.: +61-8-8201-2288

Received: 17 December 2014 / Accepted: 19 December 2014 / Published: 22 December 2014

Water is essential to all forms of life and is regarded as the most important and exploited natural resource in the world. Water moves through and is stored in different compartments of the Earth environment (atmosphere, glaciers, vegetation, soil, shallow and deep subsurface, rivers, lakes and oceans) at different velocities and quantities respectively, strongly controlled by current and past hydrometeorological and geological conditions. Understanding and quantification of the quantitative and qualitative aspects of the typical physical processes like precipitation, evaporation, transpiration, interception, infiltration, runoff, recharge, surface water and groundwater discharge form the fundamental components of the hydrological sciences. Hence, one of the definitions of hydrology is the scientific study of the occurrence, distribution, movement and properties of the waters and their interaction with the environment within each phase of the hydrologic cycle [1].

Despite the importance of global freshwater resources and of the physical understanding of the hydrological processes, the socio-economic aspects of water and the management are often as important as the physical ones. Both physical, socio-economic and management aspects of water vary strongly from region to region and over time, making the studied issues strongly multi-dimensional.

Considering above, it is clear that hydrological processes are a key component of terrestrial ecosystems, agriculture, climate, etc. This effectively results in the realization that hydrology is in essence an inter- or trans-disciplinary science with many facets. Hydrology is therefore characterized as a diverse field with many sub-disciplines with approaches from scientists and practitioners alike from a wide range of backgrounds. Hence, this scientific diversity is the beauty of this science, which we wish to nourish and further cultivate.

Thus, we are excited to introduce a new journal, Hydrology (ISSN 2306-5338), to the scientific community that offers a novel venue for sharing their latest interdisciplinary work. No better way of sharing results from such an important topic than in an open access international journal. Hydrology (ISSN 2306-5338) is based on interdisciplinary and peer-reviewed principles and covers all aspects of 
the hydrological sciences: the physical understanding of groundwater, surface water, soil water, and atmospheric water, as well as snow and ice, but equally well the socio-economic and water management aspects. More detailed scope of this journal can be found at the Hydrology editorial website [2].

Hydrology will have all the advantages of open access journals: (a) There is no limit on the length or type of submission; (b) It is committed to a rapid review process. All the papers will be under fast but rigorous peer review, if accepted, the paper will be published normally in one week; (c) All the published papers are freely accessible for anyone interested.

The Editorial Board would like to drive this new journal to a position in which it is recognized for its reputation and leading research. All research results enhancing and improving the science of hydrology are of interest for Hydrology. We invite you to submit your manuscripts or suggestions to Hydrology and we are looking forward to receiving your contributions.

\section{References}

1. What Is Hydrology and What Do Hydrologists Do? Available online: http:/water.usgs.gov/ edu/hydrology.html (accessed on 10 December 2014).

2. Hydrology. Available online: http://www.mdpi.com/journal/hydrology/about (accessed on 10 December 2014).

(C) 2014 by the authors; licensee MDPI, Basel, Switzerland. This article is an open access article distributed under the terms and conditions of the Creative Commons Attribution license (http://creativecommons.org/licenses/by/4.0/). 